\title{
The association of statins and taxanes: an efficient combination trigger of cancer cell apoptosis
}

\author{
J Follet', L Corcos', G Baffet', F Ezan', F Morel',3, B Simon' and C Le Jossic-Corcos*,1 \\ 'Inserm U6 I 3-ECLA Team, Faculté de Médecine, Université Européenne de Bretagne, Université de Bretagne Occidentale, IFR I 48-ScInBioS, 22 Avenue \\ Camille Desmoulins, 29200 Brest, France; ${ }^{2}$ CHU Brest, 5 Avenue Foch, 29200 Brest, France; ${ }^{3}$ EA SERAIC-IRSET, Faculté de Pharmacie, IFR I 40, \\ 2 Avenue du Pr Léon Bernard, 35000 Rennes, France
}

BACKGROUND: Cancer cell killing might be achieved by the combined use of available drugs. Statins are major anti-hypercholesterolemia drugs, which also trigger apoptosis of many cancer cell types, while docetaxel is a potent microtubule-stabilising agent.

METHODS: Here, we looked at the combined effects of lovastatin and docetaxel in cancer cells.

RESULTS: Whole transcriptome microarrays in HGT-I gastric cancer cells demonstrated that lovastatin strongly suppressed expression of genes involved in cell division, while docetaxel had very little transcriptional effects. Both drugs triggered apoptosis, and their combination was more than additive. A marked rise in the cell-cycle inhibitor $\mathrm{p} 21$, together with reduction of aurora kinases $\mathrm{A}$ and $\mathrm{B}$, cyclins BI and DI proteins was induced by lovastatin alone or in combination with docetaxel. The drug treatments induced the proteolytic cleavage of procaspase-3, a drop of the anti-apoptotic Mcl-I protein, Poly-ADP-Ribose Polymerase and Bax. Strikingly, docetaxel-resistant HGT-I cell derivatives overexpressing the MDR-I gene were much more sensitive to lovastatin than docetaxelsensitive cells.

CONCLUSION: These results suggest that the association of lovastatin and docetaxel, or lovastatin alone, shows promise as plausible anticancer strategies, either as a direct therapeutic approach or following acquired P-glycoprotein-dependent resistance.

British Journal of Cancer (2012) 106, 685-692. doi:10.1038/bjc.2012.6 www.bjcancer.com

Published online 31 January 2012

(c) 2012 Cancer Research UK

Keywords: statins; taxanes; gastric cancer

Gastric cancer is mostly associated with poor survival and ranks five in Europe in terms of incidence (Ferlay et al, 2010); it is also one major cause of cancer-related death worldwide. Because gastric cancer is often detected at late stages, available treatments are mostly inefficient (Shah and Kelsen, 2010). Microtubule targeting agents of the taxane class, like docetaxel, have been used for almost a decade to treat refractory breast cancer, and they have also been foreseen to treat gastric cancer. However, only few patients could benefit from docetaxel treatment, mostly because of severe side effects (Baker et al, 2009; Nishiyama and Wada, 2009). Nevertheless, many clinical trials recorded at the NIH plan to evaluate docetaxel as an anticancer agent in combination with other chemotherapeutic agents, including 5-fluorouracile, cisplatin, epirubicin, or bevacizumab, among several others (Ajani, 2008; Di Lauro et al, 2009; Goel et al, 2010; Smith et al, 2011). Hence, docetaxel is believed to be promising for the treatment of gastric cancer.

Statins are widely used as anti-hypercholesterolemia drugs, but they also bear potential as either cancer preventive or adjuvant therapies (Demierre et al, 2005; Sassano and Platanias, 2008). There has been some dispute in the literature concerning the chemoprevention statins may exert on cancer occurrence (Bjerre and

\footnotetext{
*Correspondence: Dr C Le Jossic-Corcos;

E-mail: catherine.corcos@univ-brest.fr

Revised 12 December 201 I; accepted 5 January 2012; published online 31 January 2012
}

LeLorier, 2001; Katz, 2005). By contrast, analyses in experimental models have mostly converged to suggest that statins may increase the efficacy of cancer cell killing by several classes of drugs and used to target various types of cancer cells (Graaf et al, 2004; van der Spek et al, 2009; Sane et al, 2010; Zheng et al, 2010). Hence, combinations of statins with DNA damaging agents like topoisomerase inhibitors, cisplatin, or 5-fluorouracile have shown increased cell death, reduced tumour growth, or metastases (Feleszko et al, 1998; Agarwal et al, 1999; Wang et al, 2002; Kozar et al, 2004).

The molecular mechanisms evoked in response to statins or docetaxel have been investigated in cell culture and animal models. Docetaxel promotes microtubulin assembly and stabilises the polymers against depolymerisation, thereby inhibiting microtubule dynamics (Ringel and Horwitz, 1991). As a result, mitotic progression is restricted. Statins have no reported effects on the activity of the mitotic spindle. Docetaxel triggers the degradation of the anti-apoptotic Bcl-2 protein through increased phosphorylation (Berchem et al, 1999). Similarly, statins suppress the Bcl-2 protein (Wong et al, 2002). Both docetaxel and statins inhibit angiogenesis, although this may depend on the administered dose for statins (Sweeney et al, 2001; Skaletz-Rorowski and Walsh, 2003). Statins can induce the cell-cycle inhibitor protein p21, which is also true for docetaxel (Gray-Bablin et al, 1997; Lee et al, 1998; Gan et al, 2011; Shin et al, 2011). The combination of paclitaxel and lovastatin had a synergistic effect on apoptosis of leukaemia cells (Holstein and Hohl, 2001), whereas the same combination did not show any increase in cytotoxicity in anaplastic thyroid carcinoma cells 
(Chung et al, 2011). The combination of docetaxel, which is more potent than paclitaxel, with statins has not been tested.

This study was devised to address the question of the effects of such a combined treatment in the human gastric HGT-1 cancer cell line. The results presented herein show that the association of lovastatin and docetaxel provided a more than additive apoptotic response. In addition, HGT-1-derived docetaxel-resistant cells were sensitive to statins, even more than parental HGT-1 cells. As a whole, this novel drug combination was more efficient at inducing apoptosis than either drug alone in HGT-1-sensitive cells. Lovastatin was, by itself, able to overcome the acquired resistance to docetaxel.

\section{MATERIALS AND METHODS}

\section{Cell culture}

HGT-1 human gastric cancer cells were grown at $37^{\circ} \mathrm{C}$ under a humidified atmosphere of $5 \% \mathrm{CO}_{2}$ in DMEM (Dulbecco's modified Eagle's medium) (Lonza, Saint Beauzire, France), containing $4.5 \mathrm{~g} \mathrm{~L}^{-1}$ glucose and supplemented with $5 \%$ fetal bovine serum without antibiotics (Gibco-Invitrogen, Cergy-Pontoise, France) (Laboisse et al, 1982; Gibot et al, 2009). HepG2 human hepatoblastoma (DMEM/F12, 1/1, 5\% fetal bovine serum), HeLa human cervical cancer (DMEM, 10\% fetal calf serum), and H322 human lung cancer (RPMI-1640, 10\% fetal calf serum) cells were also used (Supplementary Figure 2). All cell lines were free of mycoplasma.

Selection of the docetaxel-resistant cell populations from HGT-1 cells was performed with mass cultures grown in complete medium supplemented with $5 \mathrm{~nm}$ docetaxel. Massive cell death occurred for several weeks under continuous selective pressure, after which the populations stabilised and started to grow with no more signs of death. Cells were constantly grown in the presence of $5 \mathrm{nM}$ docetaxel, except for the cell passage that preceded the experiments that involved drug treatments.

\section{Fluorescence in-situ hybridisation}

Fluorescence in-situ hybridisation (FISH) was used to determine the number of MDR1 chromosomal copies using bacterial artificial chromosome (BAC) clones chosen from the human genome browser database of the Genome Bioinformatics Group at the University of California, Santa Cruz (http://www.genome.ucsc.edu/). BACs RP11-806M4 and RP11-42N21 were extracted using standard methods and then labelled by nick translation in spectrum orange (Abbott, Rungis, France) and in spectrum green (Abbott), respectively. Dual FISH using RP11-42N21 and RP11-806M4 was performed on HGT-1 and HGT-1-D5 cell lines according to the standard procedures (Morel et al, 2003). After hybridisation, the slides were counterstained with $4^{\prime}, 6$-diamidino-2-phenylindole and analysed with a Zeiss Axio Plan microscope (Carl Zeiss SAS, Le Pecq, France). Subsequent image acquisition was performed using a CCD camera with Isis (MetaSystems, Altlussheim, Germany). For each cell line, at least 30 metaphases were analysed.

\section{Determination of apoptotic chromatin fragmentation}

The cells were treated with different concentrations of docetaxel, lovastatin or with both. Apoptosis was determined by Hoechst $33342\left(10 \mu \mathrm{g} \mathrm{ml}^{-1}\right.$ in phosphate buffered saline (PBS)) staining of the cells for $15 \mathrm{~min}$ at $37^{\circ} \mathrm{C}$ and fluorescence microscopy analysis of 300 cells per condition, from triplicate cultures.

\section{RNA extraction and reverse transcription - PCR analysis}

Total RNA was isolated using Trizol (Invitrogen, Cergy-Pontoise, France). The integrity and purity of the RNA was determined by measuring the optical density ratio (A260/A280) and the RIN
(RNA Integrity Number) using the RNA 6000 Nano LabChip (Agilent, Massy, France) and the Agilent 2100 bioanalyzer (Agilent). The RNA samples were used for the first-strand cDNA synthesis with the High Capacity cDNA Reverse Transcription kit and random hexamer primers (Applied Biosystems, Courtaboeuf, France). Quantitative real-time reverse transcription (RT)-PCR was performed using the Power SYBR Green Kit (Applied Biosystems) according to manufacturer's instructions with an ABI 7300 real-time PCR system (Applied Biosystems). mRNA levels were analysed in duplicate, normalised against GAPDH or phospho-protein P0 as an internal control gene. The results are expressed as the relative gene expression using the $\Delta \Delta \mathrm{Ct}$ method (Livak and Schmittgen, 2001). All of the tested genes were selected based on the microarray analyses (see below). In particular, we have validated and further studied: HMGCR (encoding HMG-CoA reductase), farnesyl pyrophosphate synthase (FPPS) (also known as FDPS, Supplementary Table 2), Sterol Element Binding Protein (SREBP)-1 and SREBP-2, low-density lipoprotein receptor (LDL$\mathrm{R})$, cyclins B1 and D1, aurora kinases A and B, survivin, p21 and p27 (Supplementary Table 3). The primer sequences and reaction conditions will be provided upon request.

\section{Microarray analysis}

Double-stranded cDNA was synthesised from $500 \mathrm{ng}$ of total RNA using the Quick Amp Labeling Kit, One-color, as instructed by the manufacturer (Agilent). Labelling with cyanine3-CTP, fragmentation of cRNA, hybridisation using the whole human genome kit $(4 \times 44 \mathrm{~K})$, and washing were performed according to manufacturer's instructions (Agilent). The microarrays were scanned and the data were extracted with the Agilent Feature Extraction Software. GeneSpring GX 11.0 (Agilent) was used to compare the data from treatment conditions with control. Three independent experiments were used for this microarray analysis.

\section{Protein extraction and western blotting analysis}

The cells were harvested, washed in PBS, and lysed in RIPA buffer $(50 \mathrm{~mm}$ Tris $-\mathrm{HCl} \mathrm{pH} 7.4,150 \mathrm{~mm} \mathrm{NaCl}, 0.5 \%$ sodium deoxycholate, $0.1 \%$ SDS, $1 \%$ NP-40, $1 \mathrm{~mm}$ EDTA, and $1 \mathrm{mM}$ PMSF) containing protease inhibitor cocktail (Roche, Meylan, France) and phosphatase inhibitor (Active Motif, Rixensart, Belgium) for $10 \mathrm{~min}$ at $4^{\circ} \mathrm{C}$. Sixty micrograms of proteins were boiled in Laemmli sample buffer (Bio-Rad, Marnes la Coquette, France) for 5 min, separated by SDS - PAGE using $12 \%$ or $15 \%$ polyacrylamide gels and blotted onto polyvinyl difluoride membranes (GE Healthcare, Orsay, France). Non-specific binding sites were blocked for $1 \mathrm{~h}$ at room temperature by $5 \%(\mathrm{wt} / \mathrm{v})$ fat-free milk before overnight incubation at $4{ }^{\circ} \mathrm{C}$ with specific rabbit (or mouse for cyclin B1) anti-human antibodies: aurora kinases A and B, procaspase-3, PARP, Bcl-2, Bax, and survivin (Cell Signaling Technology, Ozyme, Saint Quentin en Yvelines, France), p27, p21, Mcl-1, cyclin B1 (Santa Cruz Biotechnology, Tebu-bio, Le Perray-enYvelines, France), cyclin D1 (NeoMarkers, Thermo Fisher Scientific, Illkirch, France), or HSC70 (Abcam, Paris, France) as a loading control. Anti-phospho-ERK1/2 was a mouse monoclonal antibody against a synthetic phosphopeptide (residues around threonine 202 and tyrosine 209 of human p44 MAPK; Cell Signaling Technology, Ozyme). Polyclonal antibodies against ERK1 (rabbit, sc-94) or ERK2 (rabbit, sc-154) and phospho-MEK1/2 were from Santa Cruz Biotechnology (Tebu-bio). Rabbit anti-phospho-JNK was from Cell Signaling and rabbit polyclonal anti-P38 antibody from Santa Cruz Biotechnology (Tebu-bio). Antibodies were used at the following dilutions: 1:500 (cyclin D1, Mcl-1, cyclin B1, p27, p21, Bax, ERK1/2, phospho-MEK1/2, p38, phospho-JNK, phosphoERK1/2), 1:1000 (Caspase-3, PARP, aurora kinases A and B, survivin), and 1:2000 (Hsc70). Primary antibodies were detected with horseradish peroxidase-conjugated IgGs (1:5000; 
GE Healthcare). Blots were revealed using an Enhanced Chemiluminescence detection kit (GE Healthcare) by the Chemi-Capt 5000 software (Vilber Lourmat, Marne la Vallée, France).

\section{RESULTS}

\section{1-Lovastatin, docetaxel, and combinations of both trigger} HGT-1 apoptosis

We have shown previously that lovastatin could induce apoptosis of HGT-1 gastric cancer cells in a dose- and time-dependent manner (Gibot et al, 2009). Pilot experiments were performed to determine what would be the best docetaxel concentrations to evaluate its effects (Supplementary Figure 1). We selected the concentrations of $12.5 \mu \mathrm{m}$ lovastatin and 5 or $10 \mathrm{~nm}$ docetaxel for $48 \mathrm{~h}$.

As shown in Figure 1, 35\% apoptosis was attained in response to $12.5 \mu \mathrm{m}$ lovastatin for $48 \mathrm{~h}$. Docetaxel also induced apoptosis, although at a lower level $(15 \%$ and $27 \%$ for 5 and $10 \mathrm{~nm}$, respectively). That docetaxel-induced apoptosis was further demonstrated by the ability of the broad spectrum caspase inhibitor Z-VAD-fmk to suppress cell death (data not shown). Strikingly, the exposure to both drugs had a more than additive effect on apoptosis (up to $80 \%$ apoptosis), when compared with the effect expected from the addition of apoptosis \% obtained for the drugs used alone $(50 \%$ and $60.5 \%$ for lovastatin + docetaxel $5 \mathrm{~nm}$ and lovastatin + docetaxel $10 \mathrm{~nm}$, respectively, $P<0.001$; Student's $t$-test). Hence, docetaxel induced apoptosis in these gastric cancer cells, and this effect was strongly enhanced by lovastatin. This drug combination $(12.5 \mu \mathrm{M}$ lovastatin $+5 \mathrm{~nm}$ docetaxel) also triggered apoptosis in other cell types, including HepG2 human hepatoblastoma, HeLa cervical cancer, and H322 lung cancer cells, as demonstrated by increased caspase 3/7 activity (Supplementary Figure 2).

\section{2-Microarray analyses reveal a wealth of changes induced by lovastatin in HGT-1 cells}

To test the effects of the drugs on gene expression profiles, HGT-1 cells were treated by $12.5 \mu \mathrm{m}$ lovastatin, $5 \mathrm{nM}$ docetaxel, or by a

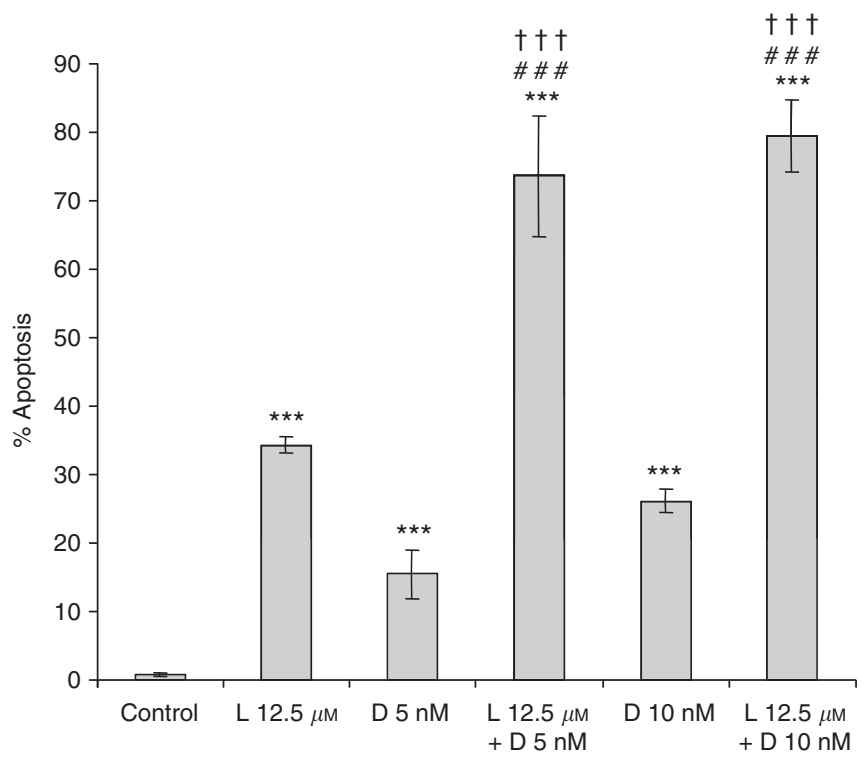

Figure I Apoptosis induction by lovastatin and docetaxel in HGT-I gastric cancer cells. HGT-I cells were treated with $12.5 \mu \mathrm{M}$ lovastatin (LI2.5) or with 5 or 10 nM docetaxel (D5 or D I0) alone or in combination for $48 \mathrm{~h}$. Apoptosis was determined by Hoechst 33342 staining. Values are means \pm s.d. $(n=6)$. ****Compared with control, \#\# compared with docetaxel treatment, ${ }^{\dagger \dagger}$ compared with lovastatin treatment $(P<0.00$ I, Student's t-test). combination of both for $48 \mathrm{~h}$. RNA was extracted and used for whole transcriptome analysis with 44k Agilent gene chips in triplicate experiments. Lovastatin induced 362 genes (two-fold variation, $P<0.01$ ) and repressed 508 genes (Supplementary Table 1). In sharp contrast, at these levels of confidence and threshold, docetaxel did not modify expression of any gene. The drug combination led to higher numbers of upregulated (499) and downregulated (552) genes than attained with lovastatin alone, indicating that both drugs interacted under these conditions. This suggests that the stronger apoptosis-inducing effect of the drug combination might result, in part, from this additional set of gene expression modifications.

Lovastatin induced many genes involved in lipid biosynthesis pathways (1.6- to 4.4-fold increases; Supplementary Table 2). By contrast, lovastatin strongly suppressed expression of many genes involved in cell division and cell-cycle progression, while increasing the $p 21$ gene that encodes a cell-cycle repressor protein (Supplementary Table 3 ).

\section{3-Lipid synthesis control is impaired in lovastatin-treated cells}

To characterise in more details the effects of the drugs on lipid synthesis genes, HGT-1 cells were treated by either lovastatin or
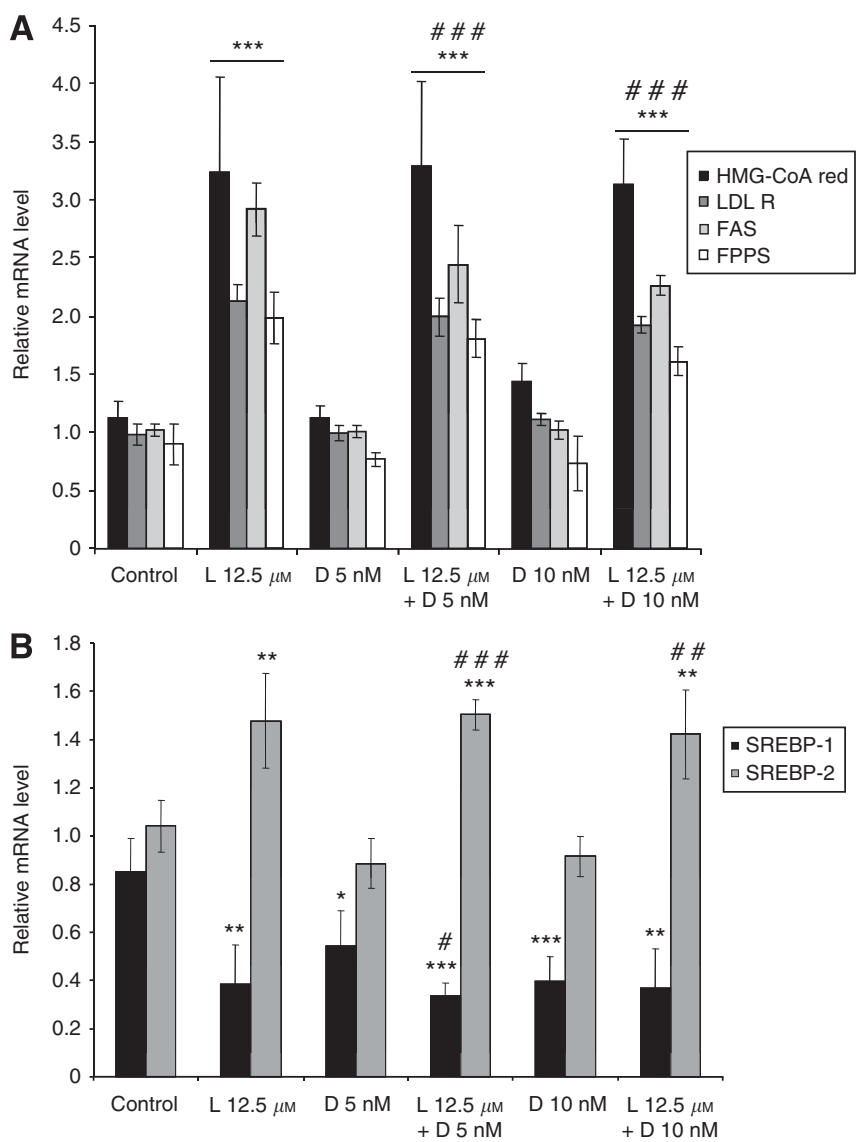

Figure 2 Effect of lovastatin and docetaxel on lipid synthesis gene expression levels. HGT-I cells were treated with $12.5 \mu \mathrm{M}$ lovastatin (L 12.5) or with 5 or $10 \mathrm{nM}$ docetaxel (D5 or D I0) alone or in combination for $48 \mathrm{~h}$. HMG-CoA reductase (HMG-CoA red), LDL receptor (LDL-R), fatty acid synthase (FAS), FPP synthase (FPPS) (A) and SREBP-I and SREBP-2 (B) mRNA levels were analysed by real-time RT-PCR (see Materials and Methods). Relative mRNA levels were normalised to PO mRNA levels. Values are means \pm s.d. $(n=4)$. *Compared with control and ${ }^{\#}$ compared with docetaxel treatment. One symbol: $P<0.05$, two symbols: $P<0.0$ l, three symbols: $P<0.00$ I (Student's $t$-test). 

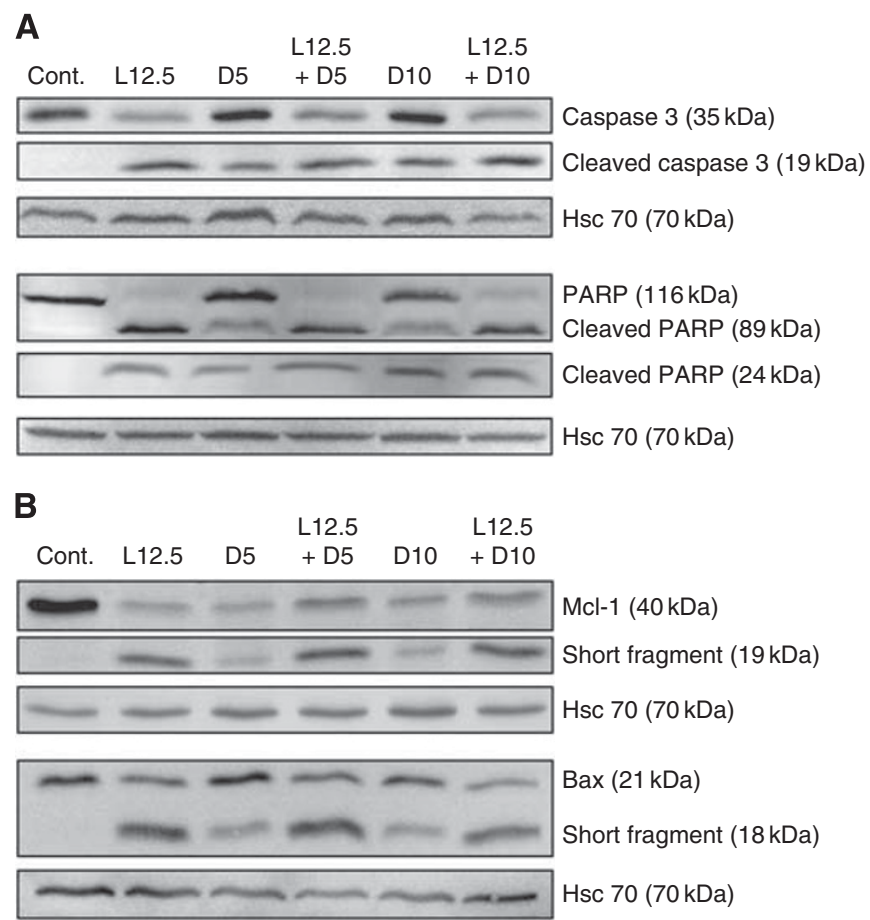

Figure 3 Effect of lovastatin and docetaxel on caspase-3, Poly-ADPRibose Polymerase (A), Mcl-I and Bax protein levels (B). HGT-I cells were treated with $12.5 \mu \mathrm{M}$ lovastatin (LI2.5) or with 5 or $10 \mathrm{nM}$ docetaxel (D5 or D I0) alone or in combination for $48 \mathrm{~h}$. Protein levels were analysed by western blotting. $\mathrm{Hsc70}$ was used as a loading control. The results are representative of three experiments with similar results.

docetaxel, or by combinations of both for $48 \mathrm{~h}$. Relative mRNA levels were determined by quantitative real-time RT-PCR. As shown in Figure 2A, the LDL-R, the HMG-CoA reductase, the FPPS, and the fatty acyl synthase (FAS) genes were all induced by lovastatin, but not by docetaxel, confirming the microarray results. The exposure to both drugs showed inductive effects similar to those obtained for lovastatin alone.

By contrast, although expression of the SREBP-2 gene was induced by lovastatin (which was not modified in the presence of docetaxel that had no effect by itself), expression of SREBP-1 was significantly reduced by all treatments (Figure $2 \mathrm{~B}$ ). Such a duality of effects on either SREBP transcript indicates that, while SREBP-2 was increased as part of the positive regulatory feedback evoked by shortage of the mevalonate pathway, the SREBP-1 gene behaved like a negative stress response gene. Expression of the SREBP-1 gene was not detected in the microarray analysis.

\section{4-Proteolytic cleavage of apoptosis proteins in response to drug treatments}

Procaspase-3 and Poly-ADP-Ribose Polymerase were cleaved in response to lovastatin and docetaxel or combination of both drugs, further demonstrating apoptosis engagement (Figure 3A). Procaspase-7 was also cleaved, especially for the highest drug concentrations (data not shown).

All treatments triggered suppression of the major anti-apoptotic Mcl-1 protein (Figure 3B). A short 19-kDa fragment appeared, resulting from apoptosis, as $\mathrm{z}-\mathrm{VAD}-\mathrm{fmk}$ prevented its appearance (data not shown). Bax, a major pro-apoptotic member of the Bcl-2 protein family, was either slightly suppressed in presence of lovastatin or combination of the two drugs, or remained unchanged in response to docetaxel. A short $18-\mathrm{kDa}$ fragment also appeared in response to the treatments, mainly in the presence

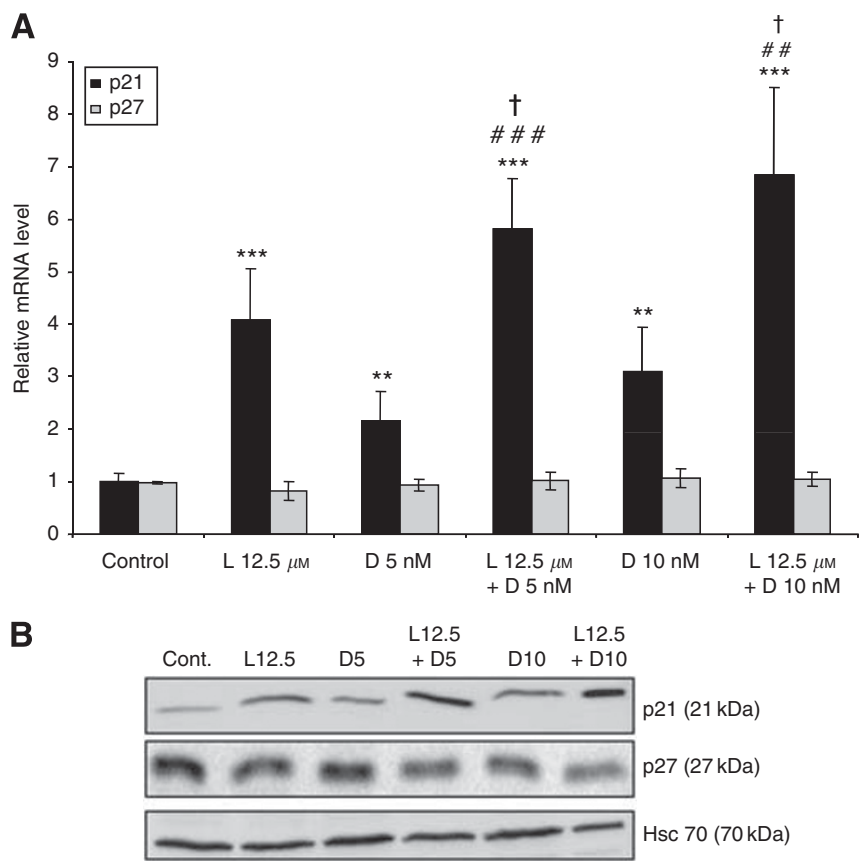

Figure 4 Effect of lovastatin and docetaxel on p2I and p27 expression. HGT-I cells were treated with $12.5 \mu \mathrm{M}$ lovastatin (LI2.5) or with 5 or $10 \mathrm{nM}$ docetaxel (D5 or D I0) alone or in combination for $48 \mathrm{~h}$. (A) p2l and p27 mRNA levels were analysed by real-time RT-PCR. Relative mRNA levels were normalised to GAPDH mRNA levels. Values are means \pm s.d. $(n=4)$. *Compared with control, ${ }^{*}$ compared with docetaxel treatment, †compared with lovastatin treatment. One symbol: $P<0.05$, two symbols: $P<0.0$ I, three symbols: $P<0.00$ I (Student's $t$-test). (B) $p 21$ and p27 protein levels were analysed by western blotting. $\mathrm{Hsc} 70$ was used as a loading control. The western blotting analyses are representative of three experiments with similar results.

of lovastatin, alone or combined, and may have been induced by caspases activity as it disappeared under treatments combined to z-VAD-fmk (data not shown).

\section{5-Cell cycle and mitosis impairment}

Since docetaxel hampers mitosis, we sought to determine the effects of lovastatin and docetaxel on p21 and p27 transcript levels. As observed in microarray experiments, the p21 transcript was induced by lovastatin (Supplementary Table 3). As shown in Figure 4A, both drugs induced p21 expression, with a more marked effect (up to four-fold) with lovastatin than for docetaxel. The drug combination led to an effect higher (up to seven-fold for $10 \mathrm{nM}$ docetaxel + lovastatin) than obtained for the drugs used as single agents. These increases in the p21 transcript were associated with a parallel increase in the p 21 protein (Figure 4B). The expression of p27 was slightly reduced by the drug combination (Figure 4B).

To analyse the effects of the drugs on proteins involved in mitosis progression, we next looked at expression of cyclin B1, cyclin D1, and aurora kinase A. As shown in Figure 5A, lovastatin reduced expression of all transcripts, both alone, in agreement with microarray experiments, or when combined with docetaxel. In addition, lovastatin repressed aurora kinase B and survivin, even more strongly than cyclin B1, cyclin D1, and aurora kinase A mRNAs, either alone or combined with docetaxel, although docetaxel induced these transcripts (mostly survivin) (Figure 5B). In addition, lovastatin alone or in combination with docetaxel triggered a decrease in all proteins. Docetaxel also triggered a decrease in aurora kinases $\mathrm{A}$ and $\mathrm{B}$, but slightly increased cyclin B1 (Figure 5C). Strikingly, docetaxel strongly 
A

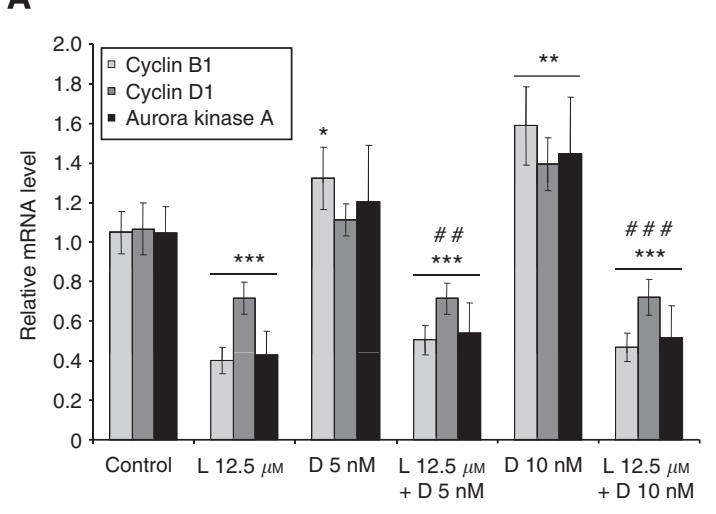

B $^{2.5}$ Aurora kinase B

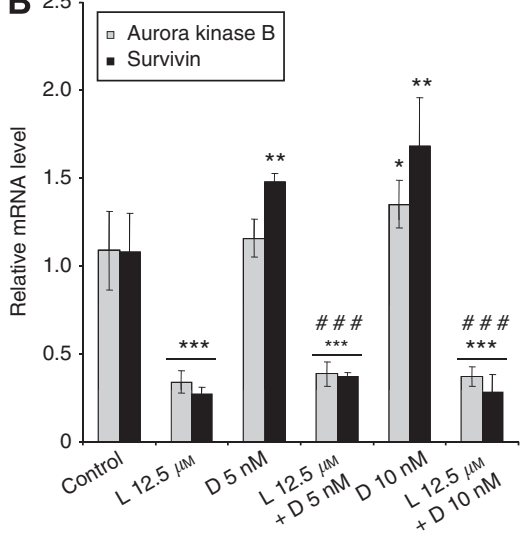

D $\quad \mathrm{L} 12.5 \quad \mathrm{~L} 12.5$

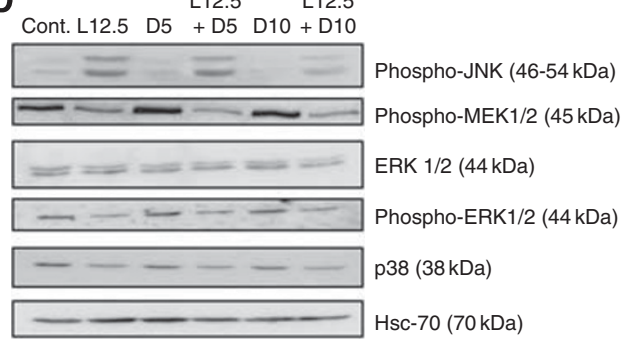

Figure 5 Effect of lovastatin and docetaxel on expression of genes involved in the initiation and progression of mitosis, cytokinesis, and MAP kinases signalling pathway. HGT-I cells were treated with $12.5 \mu \mathrm{M}$ lovastatin (LI2.5) or with 5 or $10 \mathrm{~nm}$ docetaxel (D5 or DI0) alone or in combination for $48 \mathrm{~h}$. Cyclin DI, cyclin BI, aurora kinase A (A), aurora kinase B and survivin (B) mRNA levels were analysed by real-time RT-PCR. Relative mRNA levels were normalised to P0 mRNA levels. Values are means \pm s.d. $(n=4)$. ${ }^{*}$ Compared with control, \#compared with docetaxel treatment, ${ }^{\dagger}$ compared with lovastatin treatment. One symbol: $P<0.05$, two symbols: $P<0.0$ I, three symbols: $P<0.00$ I (Student's $t$-test). (C) Cyclin BI, cyclin DI, aurora kinase $A$, aurora kinase $B$, and survivin protein levels were analysed by western blotting. Hsc70 was used as a loading control. (D) phospho-JNK, phospho-MEKI/2, ERKI/2, phospho-ERKI/2, and p38 protein levels were analysed by western blotting. Hsc70 was used as a loading control. The western blotting analyses are representative of three experiments with similar results.

induced survivin levels. However, lovastatin blocked this inducing effect, and even suppressed the protein in the combination of both drugs at the highest concentration.

Finally, we analysed expression of the jun kinase (JNK), p38 and ERK pathways in response to lovastatin and docetaxel (Figure 5D). The phosphorylated form of JNK was induced in the presence of lovastatin. Conversely, the levels of phosho-MEK1/2 and phoshoERK1/2 were decreased by lovastatin, similarly to p38 MAP kinase. We also demonstrate that docetaxel had no effect on these signalling pathways, and did not modify the effects of lovastatin when used in combination.

\section{6-Effect of the vinblastine/lovastatin combination on cell death}

As a control for the specificity of docetaxel, we used vinblastine, which acts in the reverse way as docetaxel by inhibiting the repolymerisation of microtubules. Vinblastine $(1 \mathrm{nM}, 48 \mathrm{~h})$ triggered about $30 \%$ apoptosis but did not add to the effect of lovastatin, even showing some antagonism over the expected death rate (for the $1 \mathrm{~nm}$ drug concentration; Supplementary Figure 3). Hence, these observations clearly distinguished docetaxel from vinblastine, despite the fact that both drugs could efficiently trigger apoptosis of HGT-1 cells.

\section{7-Isolation of docetaxel-resistant cells}

Drug resistance is a serious hurdle for the treatment of cancer patients. In order the look for novel ways to get around acquired resistance to docetaxel, we isolated a population derived from HGT-1 cells (named HGT-1-D5) following selection in the continuous presence of $5 \mathrm{~nm}$ docetaxel. The HGT-1-D5 cell population was also resistant to vinblastine-induced apoptosis. This resistance was fully overcome in the presence of verapamil (Supplementary Figure 4), a P-glycoprotein (Pgp, the product of the $M D R-1$ gene) blocker, indicating that one major difference between HGT-1 and HGT-1-D5 cells was at the level of expression and function of Pgp. To verify that HGT-1-D5 cells overexpressed the MDR-1 gene, we performed quantitative RT - PCR with MDR-1 primers. This analysis showed that the $M D R-1$ gene was dramatically overexpressed in HGT-1-D5 cells, whereas no signal could be obtained with the parental cells (data not shown). In addition, the expression of the other members of the $A B C$ transporters (MRP-1/2/3) was unchanged (data not shown). Hence, these results demonstrate that the acquired resistance to docetaxel of HGT-1-D5 cells was due to a massive overexpression of Pgp. To fully confirm these data, we performed a FISH analysis using probes that cover the MDR-1 gene locus. Chromosome amplification was readily detected in $47.5 \%$ of mitotic figures of HGT-1-D5 but not HGT-1 cells, in support of the overexpression of MDR-1 transcript in HGT-1-D5 cells (Supplementary Figure 5).

\section{8-Enhanced apoptosis by lovastatin in HGT-1-D5 cells}

To determine the effect of lovastatin on HGT-1-D5 cells, we treated the cells with either 2.5 or $5 \mu \mathrm{m}$ lovastatin, that is, drug concentrations lower than those used for the initial part of the study, for 48 or $72 \mathrm{~h}$. As shown in Figure 6A, both concentrations triggered a dose- and time-dependent increase in apoptosis in HGT-1 cells (up to $32 \%$ ). Strikingly, HGT-1-D5 cells were much more sensitive to lovastatin than HGT-1 cells (up to $55 \%$ apoptosis). To further characterise the docetaxel-resistant cells, we performed western blotting analyses. As shown in Figure 6B, protein levels were comparable between HGT-1 and HGT-1-D5 
A

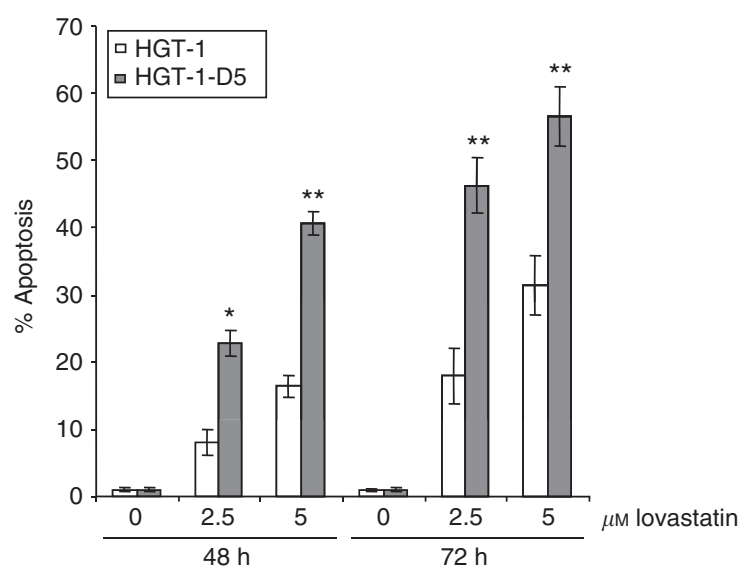

B
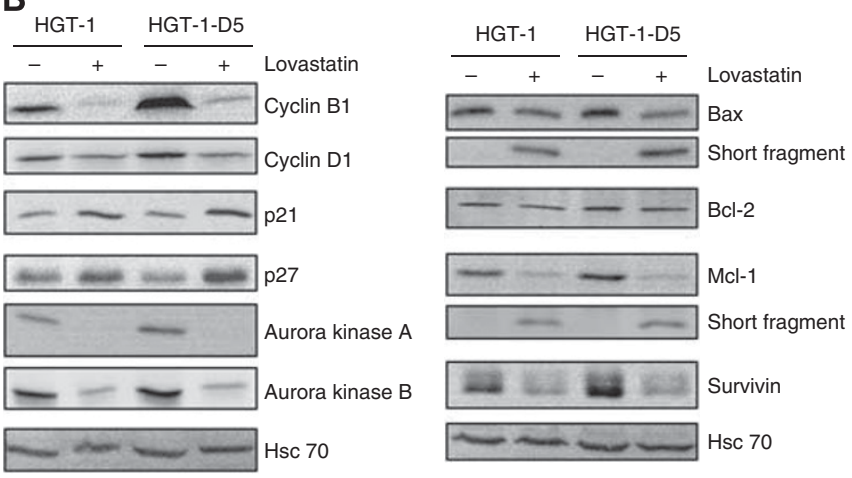

Figure 6 Comparison of the effect of lovastatin in HGT-I and HGT-I D5 cells. HGT-I and HGT-I-D5 cells were treated with $0,2.5$, or $5 \mu \mathrm{M}$ lovastatin for 48 or $72 \mathrm{~h}(\mathbf{A})$. Apoptosis was determined by Hoechst 33342 staining. Values are means \pm s.d $(n=3)$. $* P<0.1$ or $* * P<0.0$ I for HGT-I D5 cells compared with HGT-I cells (Student's t-test). (B) HGT-I and HGT-I-D5 cells were treated with $2.5 \mu \mathrm{M}$ lovastatin for $72 \mathrm{~h}$. Protein levels were analysed by western blotting. $\mathrm{Hsc70}$ was used as a loading control. The western blotting analyses are representative of three experiments with similar results.

cells, except for cyclin B1 and survivin, which were increased in HGT-1-D5 cells. Lovastatin reduced strongly (aurora kinases, Mcl-1) or more weakly (cyclin D1, Bax), or induced (p21) protein levels similarly in HGT-1 and HGT-1-D5 cells. Overexpression of survivin and cyclin B1 proteins in HGT-1-D5 cells was fully suppressed by lovastatin. In addition, lovastatin slightly induced p27 in HGT-1-D5 cells, adding a further level of cell-cycle blockade. Even though cell cycle-associated cyclin B1 or survivin was expressed at higher levels in HGT-1-D5 cells than in HGT-1 cells, this was abolished by lovastatin treatment.

\section{DISCUSSION}

The cytotoxic activity of docetaxel has been attributed to its ability to stabilise the mitotic spindle, upon blocking microtubule depolymerisation. Direct consequences of this activity were a block of the cell cycle in the G2/M transition (Fabbri et al, 2006), or in subG1 (Hernandez-Vargas et al, 2007). Quite often, this was associated with an increase in p21 (Fabbri et al, 2008). In addition, overexpression of p21 in docetaxel-resistant cells restored drug sensitivity (Canfield et al, 2006). Interestingly, survivin gene expression was inducible by docetaxel in DU145 human prostate cancer cells (Kim et al, 2006), much like we observed in HGT-1 cells. This observation could seem surprising, in view of the death potential of docetaxel treatment. However, it was shown that the increase in survivin was associated with the nuclear interaction with the pro-apoptotic Smac/DIABLO protein, which was proposed to increase cell death in this model (Kim et al, 2006). In addition, cyclin B1 was able to promote docetaxel-induced apoptosis (Gomez et al, 2007), an effect that could participate in the induction of HGT-1 apoptosis, as cyclin B1 expression was slightly induced by docetaxel. Aurora kinases A and B proteins were reduced by docetaxel treatment of HGT-1 cells, a finding in good agreement with previous studies that have clearly shown that inhibition of either kinase enhanced the cell killing activity of taxanes (Tanaka et al, 2007).

Drug combinations with taxanes have been reported to increase cell killing, as compared with the effects of single agents, either by combining dual cell death promoting activities (Bijnsdorp et al, 2008; Reiner et al, 2009) or by adding a drug efflux blocking activity to a cytotoxic effect (Miettinen et al, 2009). The interplay between microtubule poisoning and impairment of the mevalonate pathway, as analysed in this study, also proved to be remarkably efficient to induce high levels of apoptotic cell death. These events were independent on p53 as HGT-1 cells carry a mutation in the gene (Sadji-Ouatas et al, 2002). Our studies could be extended to gastric cancer cell lines that are p53 proficient, as roughly $65 \%$ of p53 proteins in gastric cancers should be wild type (Lane, 2005). Importantly, experiments conducted in HepG2 (hepatoblastoma) and HeLa (cervical cancer) cells - both carrying wild-type p53 showed strong increases in caspase-3/7 activation following combined treatment with lovastatin and docetaxel (Supplementary Figure 2). In addition, such increases in caspase-3/7 activation were also observed in $\mathrm{H} 322$ (p53 deleted, lung cancer) cells (Supplementary Figure 2).

Our results showed that, while lovastatin-induced massive changes in gene expression, docetaxel had rather limited effects. The addition of both drugs, by enlarge, gave the same repertoire of gene changes as lovastatin alone, although some additional gene expression changes were obtained by the combined treatments. As expected, lovastatin induced the SREBP-dependent gene battery. This was anticipated and was likely the result of activation of the positive feedback control mechanism that involves sterol regulatory element binding proteins (SREBP), which trans-activate these genes when mevalonate shortage occurs (Sakakura et al, 2001). In addition, lovastatin also triggered downregulation of genes involved in the control of cell division. Under our conditions, however, docetaxel had no or only little effect on gene expression at the threshold value of two-fold variation, further indicating that docetaxel-induced apoptosis mostly resulted from its direct activity onto the mitotic spindle.

At the cell level, docetaxel induced apoptosis, an effect synergistic with that of lovastatin, a potent apoptosis inducer in these cells. The links between gene expression remodelling and engagement of the apoptotic program may be plenty. However, as lovastatin suppressed the pro-survival mevalonate pathway, it is likely that mevalonate shortage had a major role in induced cell death, in spite of the stimulation of the genes from the SREBP gene battery as a rebound mechanism, an inductive response mostly unproductive since mevalonate synthesis was continuously blocked in the presence of lovastatin. Among the cell targets that may be most affected by lovastatin are the Ras, Rho, or Rab proteins that need prenylation (the post-translational addition of C15 or C20 lipid moieties to the C-terminal end of a limited subset of proteins) to anchor to the plasma membrane and gain biochemical activities (Demierre et al, 2005). This will have to be investigated in future experiments.

Both docetaxel and lovastatin suppressed the anti-apoptotic Mcl-1 protein, induced the cell-cycle inhibitor p21 mRNA and protein, and even stronger effects were obtained upon addition of both compounds. The cleavage product of the Mcl-1 protein might correspond to the one described by Cartron et al (2004), which could behave like a pro-apoptotic BH3-only protein. Docetaxel 
slightly induced cyclin B1 mRNA and protein, weakly induced cyclin D1 mRNA - but not protein, slightly increased aurora kinases mRNA, but suppressed the proteins. This could be explained by the fact that, because of cell cycle blockade, the aurora kinases could be degraded at that late $(48 \mathrm{~h})$ time point. Lovastatin suppressed cyclin B1, D1, aurora kinase A, aurora kinase $B$, and survivin mRNA levels. In addition, although docetaxel induced survivin mRNA and protein, this was abolished by lovastatin. Further experiments will be needed to explore more precisely the mechanisms involved in the repression of aurora kinases by lovastatin, an effect that has not been reported before. In addition, docetaxel induced survivin expression, despite triggering apoptosis. Therefore, it appears that docetaxel may have somewhat contradictory effects with respect to cell death and cell division control, as it may stimulate both pro-death and prosurvival pathways. By contrast, lovastatin opposed docetaxel to suppress survivin induction and promote cell death. Similarly, the caspase-mediated cleavage of $\mathrm{Mcl}-1$ and Bax, mainly resulting from lovastatin treatment, alone or combined, could amplify the apoptotic response.

Finally, the phosphorylated form of JNK was induced by lovastatin, whereas the levels of phosho-MEK1/2 and phoshoERK1/2 were decreased, similarly to p38 MAP kinase. We also demonstrate that docetaxel had no effect on JNK, p38 and ERK signalling pathways, and did not modify the effects of lovastatin when used in combination. These results were in good agreement with the ability of lovastatin to slow down cell-cycle progression and trigger cell death through induction of cell stress pathways, especially through JNK, but not p38, activation (Cerezo-Guisado et al, 2007; Liu et al, 2009).

As an approach to identify new ways to get around established resistance to docetaxel, we isolated an HGT-1 derivative cell line that was stably resistant to $5 \mathrm{~nm}$ docetaxel. This phenotype was due to the amplification of the $M D R-1$ gene locus that encodes Pgp, a specific membrane transporter protein responsible for the expulsion of many drugs, restricting their active concentration within cells and thus cytotoxic activity. Strikingly, cyclin B1 and survivin proteins were more expressed in HGT-1-D5 cells than in HGT-1 cells. When treated with lovastatin at low concentrations (2.5 and $5 \mu \mathrm{M})$, the resistant cells were shown to be exquisitely sensitive to apoptosis induction, significantly more than HGT-1 parental cells. Furthermore, p21 and p27 protein levels were induced by lovastatin in HGT-1-D5 cells. The responses of the other genes to the drugs were not different between HGT-1-D5 and HGT-1 cells. Hence, acquired resistance to docetaxel was not associated with a reduced sensitivity to lovastatin-induced apoptosis or to an inability of lovastatin to influence target protein expression. As a whole, these results demonstrate that it was possible to overcome efficiently an acquired resistance to docetaxel in human gastric

\section{REFERENCES}

Agarwal B, Bhendwal S, Halmos B, Moss SF, Ramey WG, Holt PR (1999) Lovastatin augments apoptosis induced by chemotherapeutic agents in colon cancer cells. Clin Cancer Res 5(8): 2223-2229

Ajani JA (2008) Optimizing docetaxel chemotherapy in patients with cancer of the gastric and gastroesophageal junction: evolution of the docetaxel, cisplatin, and 5-fluorouracil regimen. Cancer 113(5): 945-955

Baker J, Ajani J, Scotte F, Winther D, Martin M, Aapro MS, von Minckwitz G (2009) Docetaxel-related side effects and their management. Eur J Oncol Nurs 13(1): 49-59

Berchem GJ, Bosseler M, Mine N, Avalosse B (1999) Nanomolar range docetaxel treatment sensitizes MCF-7 cells to chemotherapy induced apoptosis, induces G2M arrest and phosphorylates bcl-2. Anticancer Res 19(1A): $535-540$

Bijnsdorp IV, Kruyt FA, Gokoel S, Fukushima M, Peters GJ (2008) Synergistic interaction between trifluorothymidine and docetaxel is sequence dependent. Cancer Sci 99(11): 2302-2308 cancer cells upon using lovastatin at concentrations that were close to those attainable in serum (Thibault et al, 1996). Importantly, the concentrations of docetaxel used in this model in-vitro system were far below what is used for cancer treatment, as clinically relevant concentrations of plasma docetaxel range between 1.5 and $6 \mu \mathrm{M}$ (Urien et al, 1996). By extension, our results might also apply to other chemotherapeutics-dependent resistance resulting from $M D R-1$ gene overexpression.

This study brings in new lights into the mechanisms evoked by both docetaxel and lovastatin to reduce cell division and increase apoptotic cell death. Hence, it will be fair to assume that such a combination of compounds could offer new therapeutic options for the treatment of gastric cancer. Furthermore, our data suggest that, should resistance to anticancer agents due to a stable MDR-1 overexpression occur, this may be efficiently overcome through the use of lovastatin in adjuvant therapies. Moreover, the treatment of lovastatin-resistant HGT-1-derived cells (Gibot et al, 2009) by docetaxel triggered apoptosis at a higher level than for HGT-1 parental cells (data not shown). The same reasoning as above can be made: in case of 'resistance' to statins - as may have occurred over years of statin therapy, or inter-individual variability - the use of docetaxel could open new treatment options for human patients.

In summary, our study has shown the potential of the docetaxel + lovastatin combination for the efficient induction of human gastric cancer cell death, among other tumour types, and the ability of lovastatin to trigger apoptosis of cancer cells overexpressing the $M D R-1$ gene. This may open the path to clinical trials for patients suffering from gastric cancers. The fact that statins are widely used in the human population without provoking deleterious effects would make this strategy readily acceptable.

\section{ACKNOWLEDGEMENTS}

We thank Dr S Jacolot and M Pesson for their help with analysis of the microarray data and Dr JP Metges for thoughtful discussions about gastric cancer. This work was supported by the INSERM, the Cancéropole Grand Ouest, the Ligue Contre le Cancer, the Association of Research on Cancer (ARC), OSEO (BioIntelligence program), the Université de Bretagne Occidentale, and the Faculté de Médecine Brest. JF was recipient of a fellowship from the Région Bretagne.

\section{Conflict of interest}

The authors declare no conflict of interest.

Supplementary Information accompanies the paper on British Journal of Cancer website (http://www.nature.com/bjc)
Bjerre LM, LeLorier J (2001) Do statins cause cancer? A meta-analysis of large randomized clinical trials. Am J Med 110(9): 716-723

Canfield SE, Zhu K, Williams SA, McConkey DJ (2006) Bortezomib inhibits docetaxel-induced apoptosis via a p21-dependent mechanism in human prostate cancer cells. Mol Cancer Ther 5(8): 2043-2050

Cartron PF, Oliver L, Juin P, Meflah K, Vallette FM (2004) The p18 truncated form of Bax behaves like a Bcl-2 homology domain 3-only protein. J Biol Chem 279(12): 11503-11512

Cerezo-Guisado MI, Alvarez-Barrientos A, Argent R, Garcia-Marin LJ, Bragado MJ, Lorenzo MJ (2007) c-Jun N-terminal protein kinase signalling pathway mediates lovastatin-induced rat brain neuroblast apoptosis. Biochim Biophys Acta 1771(2): 164-176

Chung YS, Cho S, Ryou HJ, Jee HG, Choi JY, Yoon K, Choi HJ, Lee KE, Suh YJ, Oh SK, Youn YK (2011) Is there a treatment advantage when paclitaxel and lovastatin are combined to dose anaplastic thyroid carcinoma cell lines? Thyroid 21(7): $735-744$ 
Demierre MF, Higgins PD, Gruber SB, Hawk E, Lippman SM (2005) Statins and cancer prevention. Nat Rev Cancer 5(12): 930-942

Di Lauro L, Giacinti L, Arena MG, Sergi D, Fattoruso SI, Giannarelli D, Lopez M (2009) Phase II study of epirubicin, oxaliplatin and docetaxel combination in metastatic gastric or gastroesophageal junction adenocarcinoma. J Exp Clin Cancer Res 28: 34

Fabbri F, Amadori D, Carloni S, Brigliadori G, Tesei A, Ulivi P, Rosetti M, Vannini I, Arienti C, Zoli W, Silvestrini R (2008) Mitotic catastrophe and apoptosis induced by docetaxel in hormone-refractory prostate cancer cells. J Cell Physiol 217(2): 494-501

Fabbri F, Carloni S, Brigliadori G, Zoli W, Lapalombella R, Marini M (2006) Sequential events of apoptosis involving docetaxel, a microtubuleinterfering agent: a cytometric study. BMC Cell Biol 7: 6

Feleszko W, Zagozdzon R, Golab J, Jakobisiak M (1998) Potentiated antitumour effects of cisplatin and lovastatin against MmB16 melanoma in mice. Eur J Cancer 34(3): 406-411

Ferlay J, Parkin DM, Steliarova-Foucher E (2010) Estimates of cancer incidence and mortality in Europe in 2008. Eur J Cancer 46(4): 765-781

Gan L, Wang J, Xu H, Yang X (2011) Resistance to docetaxel-induced apoptosis in prostate cancer cells by p38/p53/p21 signaling. Prostate 71: $1158-1166$

Gibot L, Follet J, Metges JP, Auvray P, Simon B, Corcos L, Le Jossic-Corcos C (2009) Human caspase 7 is positively controlled by SREBP-1 and SREBP-2. Biochem J 420(3): 473-483

Goel G, Jauhri M, Negi A, Aggarwal S (2010) Feasibility study of docetaxel, oxaliplatin and capecitabine combination regimen in advanced gastric or gastroesophageal adenocarcinoma. Hematol Oncol Stem Cell Ther 3(2): 55 - 59

Gomez LA, de Las Pozas A, Reiner T, Burnstein K, Perez-Stable C (2007) Increased expression of cyclin B1 sensitizes prostate cancer cells to apoptosis induced by chemotherapy. Mol Cancer Ther 6(5): 1534-1543

Graaf MR, Richel DJ, van Noorden CJ, Guchelaar HJ (2004) Effects of statins and farnesyltransferase inhibitors on the development and progression of cancer. Cancer Treat Rev 30(7): 609-641

Gray-Bablin J, Rao S, Keyomarsi K (1997) Lovastatin induction of cyclindependent kinase inhibitors in human breast cells occurs in a cell cycleindependent fashion. Cancer Res 57(4): 604-609

Hernandez-Vargas H, Palacios J, Moreno-Bueno G (2007) Telling cells how to die: docetaxel therapy in cancer cell lines. Cell Cycle 6(7): 780-783

Holstein SA, Hohl RJ (2001) Synergistic interaction of lovastatin and paclitaxel in human cancer cells. Mol Cancer Ther 1(2): 141 - 149

Katz MS (2005) Therapy insight: Potential of statins for cancer chemoprevention and therapy. Nat Clin Pract Oncol 2(2): 82-89

Kim JY, Chung JY, Lee SG, Kim YJ, Park JE, Yoo KS, Yoo YH, Park YC, Kim BG, Kim JM (2006) Nuclear interaction of Smac/DIABLO with Survivin at G2/M arrest prompts docetaxel-induced apoptosis in DU145 prostate cancer cells. Biochem Biophys Res Commun 350(4): 949-954

Kozar K, Kaminski R, Legat M, Kopec M, Nowis D, Skierski JS, Koronkiewicz M, Jakobisiak M, Golab J (2004) Cerivastatin demonstrates enhanced antitumor activity against human breast cancer cell lines when used in combination with doxorubicin or cisplatin. Int J Oncol 24(5): 1149-1157

Laboisse CL, Augeron C, Couturier-Turpin MH, Gespach C, Cheret AM, Potet F (1982) Characterization of a newly established human gastric cancer cell line HGT-1 bearing histamine H2-receptors. Cancer Res 42(4): 1541 - 1548

Lane DP (2005) Exploiting the p53 pathway for the diagnosis and therapy of human cancer. Cold Spring Harb Symp Quant Biol 70: 489-497

Lee SJ, Ha MJ, Lee J, Nguyen P, Choi YH, Pirnia F, Kang WK, Wang XF, Kim SJ, Trepel JB (1998) Inhibition of the 3-hydroxy-3-methylglutarylcoenzyme A reductase pathway induces p53-independent transcriptional regulation of $\mathrm{p} 21$ (WAF1/CIP1) in human prostate carcinoma cells. J Biol Chem 273(17): $10618-10623$

Liu H, Liang SL, Kumar S, Weyman CM, Liu W, Zhou A (2009) Statins induce apoptosis in ovarian cancer cells through activation of JNK and enhancement of Bim expression. Cancer Chemother Pharmacol 63(6): $997-1005$

Livak KJ, Schmittgen TD (2001) Analysis of relative gene expression data using real-time quantitative PCR and the 2(-Delta Delta $\mathrm{C}(\mathrm{T})$ ) Method. Methods 25(4): $402-408$

Miettinen S, Grenman S, Ylikomi T (2009) Inhibition of P-glycoproteinmediated docetaxel efflux sensitizes ovarian cancer cells to concomitant docetaxel and SN-38 exposure. Anticancer Drugs 20(4): 267-276
Morel F, Bris MJ, Herry A, Calvez GL, Marion V, Abgrall JF, Berthou C, Braekeleer MD (2003) Double minutes containing amplified bcr-ab fusion gene in a case of chronic myeloid leukemia treated by imatinib. Eur J Haematol 70(4): 235-239

Nishiyama M, Wada S (2009) Docetaxel: its role in current and future treatments for advanced gastric cancer. Gastric Cancer 12(3): 132 - 141

Reiner T, de las Pozas A, Gomez LA, Perez-Stable C (2009) Low dose combinations of 2-methoxyestradiol and docetaxel block prostate cancer cells in mitosis and increase apoptosis. Cancer Lett 276(1): $21-31$

Ringel I, Horwitz SB (1991) Studies with RP 56976 (taxotere): a semisynthetic analogue of taxol. J Natl Cancer Inst 83(4): 288-291

Sadji-Ouatas Z, Lasfer M, Julien S, Feldmann G, Reyl-Desmars F (2002) Doxorubicin and octreotide induce a $40 \mathrm{kDa}$ breakdown product of p53 in human hepatoma and tumoral colon cell lines. Biochem J 364(Pt 3): 881 - 885

Sakakura Y, Shimano H, Sone H, Takahashi A, Inoue N, Toyoshima $\mathrm{H}$, Suzuki S, Yamada N (2001) Sterol regulatory element-binding proteins induce an entire pathway of cholesterol synthesis. Biochem Biophys Res Commun 286(1): $176-183$

Sane KM, Mynderse M, Lalonde DT, Dean IS, Wojtkowiak JW, Fouad F, Borch RF, Reiners Jr JJ, Gibbs RA, Mattingly RR (2010) A novel geranylgeranyl transferase inhibitor in combination with lovastatin inhibits proliferation and induces autophagy in STS-26T MPNST cells. $J$ Pharmacol Exp Ther 333(1): 23-33

Sassano A, Platanias LC (2008) Statins in tumor suppression. Cancer Lett 260(1-2): $11-19$

Shah MA, Kelsen DP (2010) Gastric cancer: a primer on the epidemiology and biology of the disease and an overview of the medical management of advanced disease. J Natl Compr Canc Netw 8(4): 437 - 447

Shin HJ, Kim do N, Lee SK (2011) Association between Epstein-Barr virus infection and chemoresistance to docetaxel in gastric carcinoma. Mol Cells 32(2): $173-179$

Skaletz-Rorowski A, Walsh K (2003) Statin therapy and angiogenesis. Curr Opin Lipidol 14(6): 599-603

Smith IE, Pierga JY, Biganzoli L, Cortes-Funes H, Thomssen C, Pivot X, Fabi A, Xu B, Stroyakovskiy D, Franke FA, Kaufman B, Mainwaring P, Pienkowski T, De Valk B, Kwong A, Gonzalez-Trujillo JL, Koza I, Petrakova K, Pereira D, Pritchard KI (2011) First-line bevacizumab plus taxane-based chemotherapy for locally recurrent or metastatic breast cancer: safety and efficacy in an open-label study in 2,251 patients. Ann Oncol 22(3): $595-602$

Sweeney CJ, Miller KD, Sissons SE, Nozaki S, Heilman DK, Shen J, Sledge Jr GW (2001) The antiangiogenic property of docetaxel is synergistic with a recombinant humanized monoclonal antibody against vascular endothelial growth factor or 2-methoxyestradiol but antagonized by endothelial growth factors. Cancer Res 61(8): 3369-3372

Tanaka E, Hashimoto Y, Ito T, Kondo K, Higashiyama M, Tsunoda S, Ortiz C, Sakai Y, Inazawa J, Shimada Y (2007) The suppression of aurora-A/STK15/ BTAK expression enhances chemosensitivity to docetaxel in human esophageal squamous cell carcinoma. Clin Cancer Res 13(4): 1331-1340

Thibault A, Samid D, Tompkins AC, Figg WD, Cooper MR, Hohl RJ, Trepel J, Liang B, Patronas N, Venzon DJ, Reed E, Myers CE (1996) Phase I study of lovastatin, an inhibitor of the mevalonate pathway, in patients with cancer. Clin Cancer Res 2(3): 483-491

Urien S, Barre J, Morin C, Paccaly A, Montay G, Tillement JP (1996) Docetaxel serum protein binding with high affinity to alpha 1-acid glycoprotein. Invest New Drugs 14(2): 147-151

van der Spek E, Bloem AC, Lokhorst HM, van Kessel B, Bogers-Boer L, van de Donk NW (2009) Inhibition of the mevalonate pathway potentiates the effects of lenalidomide in myeloma. Leuk Res 33(1): 100-108

Wang W, Collie-Duguid E, Cassidy J (2002) Cerivastatin enhances the cytotoxicity of 5-fluorouracil on chemosensitive and resistant colorectal cancer cell lines. FEBS Lett 531(3): 415-420

Wong WW, Dimitroulakos J, Minden MD, Penn LZ (2002) HMG-CoA reductase inhibitors and the malignant cell: the statin family of drugs as triggers of tumor-specific apoptosis. Leukemia 16(4): 508-519

Zheng X, Cui XX, Gao Z, Zhao Y, Lin Y, Shih WJ, Huang MT, Liu Y, Rabson A, Reddy B, Yang CS, Conney AH (2010) Atorvastatin and celecoxib in combination inhibits the progression of androgen-dependent LNCaP xenograft prostate tumors to androgen independence. Cancer Prev Res (Phila) 3(1): 114-124

This work is published under the standard license to publish agreement. After 12 months the work will become freely available and the license terms will switch to a Creative Commons Attribution-NonCommercial-Share Alike 3.0 Unported License. 